\title{
Tetrathiobacter kashmirensis gen. nov., sp. nov., a novel mesophilic, neutrophilic, tetrathionate-oxidizing, facultatively chemolithotrophic betaproteobacterium isolated from soil from a temperate orchard in Jammu and Kashmir, India
}

Correspondence Wriddhiman Ghosh Wriman@rediffmail.com

\author{
Wriddhiman Ghosh, ${ }^{1}$ Angshuman Bagchi, ${ }^{2}$ Sukhendu Mandal, ${ }^{1}$ \\ Bomba Dam ${ }^{1}$ and Pradosh Roy ${ }^{1}$ \\ Department of Microbiology ${ }^{1}$ and Bioinformatics Center ${ }^{2}$, Bose Institute, P-1/12 C. I. T. \\ Scheme, VII M, Kolkata - 700 054, India
}

More than a century ago, Nathansohn (1902) described the first small, unicellular, Gram-negative bacterium capable of utilizing thiosulfate as a substrate for chemolithotrophic growth ['thiotroph', after Kelly (1989)]. For almost a century after this initial description, the metabolic ability to grow on

Published online ahead of print on 29 April 2005 as DOI 10.1099/ ijs.0.63595-0.

The GenBank/EMBL/DDBJ accession numbers for the 16S rRNA gene sequences of strains WTO0 $1^{\top}, 445 a, 445 c$, WGT and WPT and are AJ864470-AJ864474, respectively.

An example AFLP PCR profile and a UPGMA phenogram are available as supplementary material in IJSEM Online. reduced sulfur compounds as an energy and electron source was attributed to the so-called thiobacilli (Kelly, 1989), under which a huge number of species were accommodated. However, recent advances in molecular systematics have brought about a thorough reorganization of this heterogeneous and artificial genus Thiobacillus (Kelly, 1989), leading to a progressive widening of the phylogenetic and ecological spectra over which the thiotrophs are distributed (Fuchs et al., 1996; Das et al., 1996; Deb et al., 2004). The systematic diversity (McDonald et al., 1997; Moreira \& Amils, 1997; Kelly \& Wood, 2000) of sulfur chemolithotrophy is compounded by an apparent physiological multiplicity pertaining to the differential ability of organisms to utilize various reduced sulfur compounds as 
chemolithotrophic substrates (Katayama et al., 1995; Kelly et al., 1997, 2000; Friedrich, 1998). Genetic studies with both chemo- and photolithotrophic sulfur-oxidizing alphaproteobacteria have led to the identification of a sulfur oxidation (sox) gene cluster that encodes a sulfur-oxidizing multienzyme complex (Friedrich et al., 2001; Appia-Ayme et al., 2001) governing the oxidation of thiosulfate, sulfite, sulfide and elemental sulfur. Interestingly, the proposed mechanism does not account for the dissimilatory oxidation of tetrathionate, which is utilized chemolithotrophically by many species belonging to the 'Alphaproteobacteria', 'Betaproteobacteria' and 'Gammaproteobacteria' (Kelly et al., 1997, 2000; Mukhopadhyaya et al., 2000).

5S rRNA gene sequence analysis had earlier identified a phylogenetic cluster in which the mixotrophic sulfuroxidizing betaproteobacterial species of Thiomonas were clustered with species belonging to Pseudomonas, Burkholderia, Alcaligenes and Bordetella (Lane et al., 1985; Moreira \& Amils, 1997), while 16S rRNA gene sequencebased phylogeny had indicated the obligately thermophilic chemolithotroph Thermothrix azorensis to be closely related to species of Alcaligenes, Pseudomonas and Burkholderia (Odintsova et al., 1996). However, investigation with different hydrogen-oxidizing bacteria by Friedrich \& Mitrenga (1981) had shown that Alcaligenes eutrophus and Alcaligenes paradoxus (weak reaction) do not oxidize thiosulfate.

From soil samples from a temperate orchard, we have isolated and characterized 12 mesophilic, neutrophilic and facultatively sulfur-chemolithoautotrophic strains that could grow on thiosulfate and tetrathionate. Polyphasic taxonomic studies were performed upon five representative strains to delineate the taxonomic identity of the isolates. It was found that these isolates, affiliated phylogenetically to the 'Betaproteobacteria', were physiologically and biochemically similar to members of the Alcaligenaceae and belonged to a novel genus and species, for which we propose the name Tetrathiobacter kashmirensis gen. nov., sp. nov.

Three bulk-soil samples from a temperate apple orchard at Panthchawk in Srinagar in the state of Jammu and Kashmir, India, were collected and supplemented with $\mathrm{Na}_{2} \mathrm{~S}_{2} \mathrm{O}_{3} .5 \mathrm{H}_{2} \mathrm{O}(5 \%)$ and elemental sulfur powder $(5 \%)$ and incubated at $30^{\circ} \mathrm{C}$ for 2 weeks with intermittent sprinkling of sterile water. Enriched soil samples were added $(1 \% \mathrm{w} / \mathrm{v})$ to MSTY broth, a modified basal and mineral salts (MS) solution (Mukhopadhyaya et al., 2000) supplemented with sodium thiosulfate $(20 \mathrm{mM}$ $\mathrm{Na}_{2} \mathrm{~S}_{2} \mathrm{O}_{3} \cdot 5 \mathrm{H}_{2} \mathrm{O}$ ) and $5 \mathrm{~g}$ yeast extract $\mathrm{l}^{-1}$. The soil-MSTY broth mixture was incubated at $30^{\circ} \mathrm{C}$ on a rotary shaker until the colour of phenol red indicator added to the medium changed yellow. Serial dilutions from this mixture were plated on MSTY agar and incubated at $30^{\circ} \mathrm{C}$. Twelve neutrophilic, mesophilic and facultatively sulfurchemolithotrophic bacterial strains distinguished in terms of colony morphology and rate and extent of acid production in chemolithotrophic media MST (MS-thiosulfate;
$20 \mathrm{mM} \mathrm{Na} \mathrm{N}_{2} \mathrm{~S}_{2} \cdot 5 \mathrm{H}_{2} \mathrm{O}$ ) and MSTr (MS-tetrathionate; $20 \mathrm{mM} \mathrm{K} \mathrm{S}_{4} \mathrm{O}_{6}$ ) and mixotrophic media MSTY (details above) and MSTrY (MS-tetrathionate-yeast extract) were isolated as pure cultures and subjected to further studies. The new isolates were maintained in Luria-Bertani (LB) broth.

Chemolithotrophic and chemo-organotrophic growth experiments were performed at $30^{\circ} \mathrm{C}$ in MS solutions supplemented with sulfur compounds or single carbon sources, respectively. To test the chemo-organotrophic utilization of various carbon sources, basal MS solution plus one organic carbon source at a concentration of $5 \mathrm{~g} \mathrm{l}^{-1}$ was used. All the isolates were tested for their ability to use thiosulfate $(20 \mathrm{mM})$, tetrathionate $(10 \mathrm{mM})$, sulfide $(2 \mathrm{mM})$, sulfite $(3 \mathrm{mM})$, thiocyanate $(2$ and $5 \mathrm{mM})$, elemental sulfur $(0.5$ and $1.0 \% \mathrm{w} / \mathrm{v})$ or arsenite $(5 \mathrm{mM})$ as substrates for chemolithotrophic growth. Phenol red was added (final concentration of $20 \mathrm{mg} \mathrm{l}^{-1}$ ) as a $\mathrm{pH}$ indicator in media containing reduced sulfur compounds. To test mixotrophic utilization of sulfur compounds, $5 \mathrm{~g}$ yeast extract $1^{-1}$ was added to the above formulations. The level of thiosulfate or tetrathionate in the medium was estimated by the cyanolytic method described by Kelly \& Wood (1994). All other phenotypic tests were performed using standard techniques described elsewhere (Gerhardt et al., 1994). A numerical analysis of all the available comparative physiological, biochemical and chemotaxonomic data was performed using the simple matching coefficient $\left(S_{\mathrm{SM}}\right)$ and the Jaccard coefficient $\left(S_{\mathrm{J}}\right)$ (Sneath \& Sokal, 1973) followed by generation of phenograms using the UPGMA algorithm. Similar phenograms were generated with the two coefficients.

Cells of all 12 new isolates were Gram-negative, nonflagellated and oval to coccoid in shape and occurred singly or in pairs, chains, branched chains or clusters. Transmission electron micrographs revealed capsular coverings around the cells (Fig. 1). Colonies grown on LB agar plates

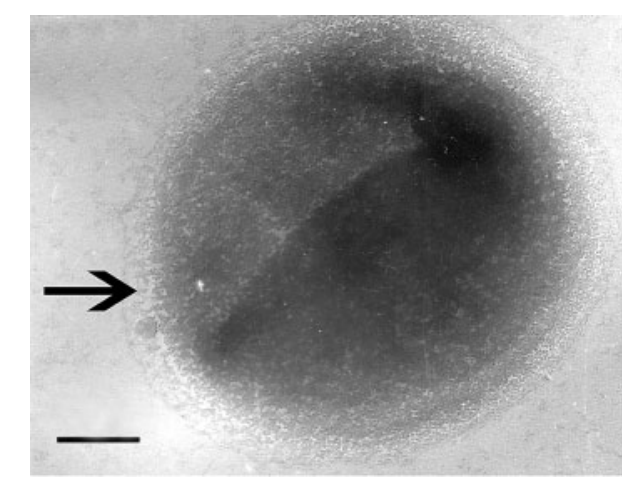

Fig. 1. Transmission electron micrograph of a cell of Tetrathiobacter kashmirensis $\mathrm{WTO01}^{\top}$ at $\times 30000$ magnification. The arrow points to the capsular covering around the cell. Bar, $0.4 \mu \mathrm{m}$. 
were circular, entire, smooth, opaque and creamy white, reaching $4-6 \mathrm{~mm}$ in diameter after incubation for 2-3 days. On MSTY agar, colonies were smooth, glossy, concavely elevated and developed a central dark mound that was rusty red. The cells developed visible colonies on MST or MSTr agar plates after 4-6 days of incubation and the phenol red indicator turned completely yellow. Growth of all the isolates was completely inhibited by $200 \mu \mathrm{g}$ ampicillin, $150 \mu \mathrm{g}$ streptomycin, $100 \mu \mathrm{g}$ nalidixic acid or rifampicin, $50 \mu \mathrm{g}$ chloramphenicol, $40 \mu \mathrm{g}$ neomycin and $20 \mu \mathrm{g}$ tetracycline $\mathrm{ml}^{-1}$.

The bacteria could grow chemolithoautotrophically on reduced sulfur compounds or chemo-organoheterotrophically on several single carbon sources and required no yeast extract or vitamins under either conditions. All the isolates were facultative chemolithotrophs and showed similar phenotypes when grown with thiosulfate or tetrathionate as energy and electron source. Thiocyanate, soluble sulfides, elemental sulfur, sulfite and arsenite were not utilized for growth nor were they oxidized under the experimental conditions used. All the strains exhibited similar kinetics of sulfur compound oxidation (data not shown).

When batch cultures of the strains were grown in thiosulfate-containing mixotrophic (MSTY) or chemolithotrophic (MST) media (both containing $20 \mathrm{mM}$ sodium thiosulfate, equivalent to $40 \mu \mathrm{g}$ atoms sulfur $\mathrm{ml}^{-1}$ ) with an initial $\mathrm{pH}$ of $7-7 \cdot 5$, there was an initial increase in $\mathrm{pH}$ up to 8.5 in the first 2 days of incubation. Subsequently, the $\mathrm{pH}$ of the two media came down to $5 \cdot 5-5 \cdot 7$ over the next 2-3 days. Growth in MSTY or MST media involved consumption of $70-80 \%$ of the thiosulfate in $4-5$ days. In MSTr medium $(10 \mathrm{mM}$ potassium tetrathionate, equivalent to $40 \mu \mathrm{g}$ atoms sulfur $\mathrm{ml}^{-1}$ ), with an initial $\mathrm{pH}$ of $7 \cdot 5$, consumption of tetrathionate and a concomitant decrease in $\mathrm{pH}$ of the medium was recorded for all 12 strains. After 4 days of growth at $30^{\circ} \mathrm{C}$, all strains exhibited utilization of approximately $80 \%$ of the tetrathionate and the $\mathrm{pH}$ of the spent medium was between 5 and $5 \cdot 5$.

Details of chemolithotrophic growth coupled with oxidation of thiosulfate or tetrathionate were studied in the representative strain $\mathrm{WT} 001^{\mathrm{T}}$ using an initial concentration of $20 \mathrm{mM}$ sodium thiosulfate and $10 \mathrm{mM}$ tetrathionate with subsequent periodic addition of the same amounts of filter-sterilized sodium thiosulfate or potassium tetrathionate solutions to the respective cultures over a total incubation period of $144 \mathrm{~h}$ (Fig. 2a, b). Utilization of $200 \mu \mathrm{g}$ atoms sulfur $\mathrm{ml}^{-1}$ supported a final $\mathrm{OD}_{600}$ of $0 \cdot 47$ and 0.43 in the two media types, MST and MSTr, respectively, and a cellular yield of 500-600 mg cell protein ( $\mathrm{g}$ atoms sulfur oxidized) ${ }^{-1}$ was observed on both thiosulfate and tetrathionate. During chemolithotrophic growth on thiosulfate, the thiosulfate was converted to tetrathionate almost in equivalents with respect to sulfur atoms (Fig. 2b), which was then converted entirely to sulfate, as evident from the concomitant lowering of $\mathrm{pH}$ of the spent medium.
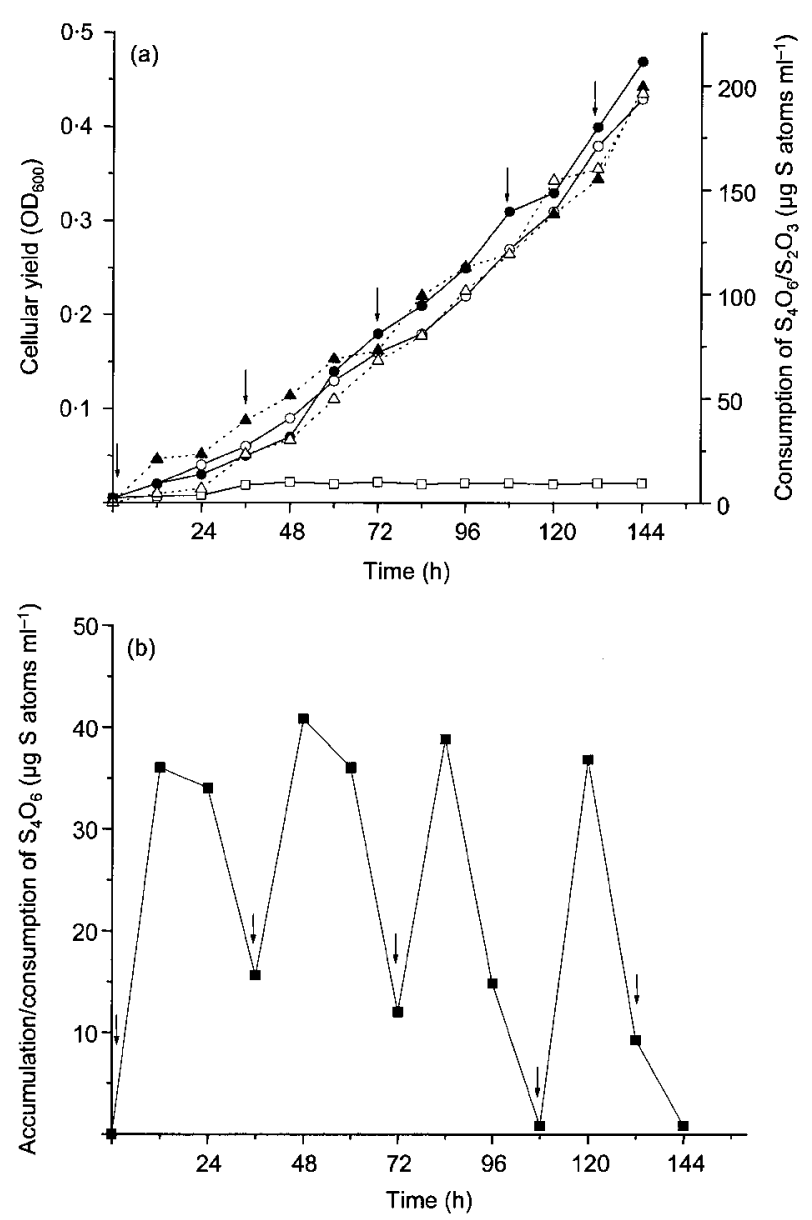

Fig. 2. Chemolithotrophic growth coupled with the oxidation of thiosulfate or tetrathionate by $\mathrm{WTO}^{\mathrm{T}}{ }^{\top}$ using initial concentrations of $5 \mathrm{~g}$ thiosulfate or $3 \mathrm{~g}$ tetrathionate $\mathrm{I}^{-1}$ (both equivalent to $40 \mu \mathrm{g}$ atoms sulfur $\mathrm{ml}^{-1}$ ). Periodically, the same amounts of filter-sterilized sodium thiosulfate or potassium tetrathionate solutions were added four times to the respective cultures over a total incubation period of $144 \mathrm{~h}$, which amounted to a total of $200 \mu \mathrm{g}$ atoms sulfur $\mathrm{ml}^{-1}$ in both media. Cells were grown in MST or MSTr medium for $20 \mathrm{~h}$ and $1 \%$ inocula were transferred to MS (control), MST or MSTr media. Cultures were incubated at $30^{\circ} \mathrm{C}$ with shaking and sterile sodium carbonate solution (2 M) was added periodically to the flasks to adjust the $\mathrm{pH}$ of the medium to $7 \cdot 4$. (a) Solid and dotted lines respectively represent cellular yield and sulfur compound consumption for growth in control MS medium ( $\square$ ), MST medium $(\boldsymbol{O}, \boldsymbol{\Delta})$ and $\operatorname{MSTr}$ medium $(\bigcirc, \triangle)$. Downward arrows indicate the times when filter-sterilized sodium thiosulfate $\left(5 \mathrm{gl}^{-1}\right)$ or potassium tetrathionate $\left(3 \mathrm{~g} \mathrm{I}^{-1}\right)$ solutions were added to the respective cultures. (b) Successive accumulation and consumption of tetrathionate over time by $\mathrm{WTOO} 1^{\top}$ during growth in MST medium. The tetrathionate concentration (in $\mu \mathrm{g}$ atoms sulfur $\mathrm{ml}^{-1}$ ) in the spent medium is indicated. Downward arrows indicate times when filter-sterilized sodium thiosulfate $\left(5 \mathrm{~g} \mathrm{I}^{-1}\right)$ solution was added. 
High-molecular-mass DNA was prepared as described by Ezaki et al. (1988) with minor modifications. No hybridization was detected (data not shown) when double-digested genomic DNA of all the isolates was transferred onto a nylon membrane and hybridized with DIG-labelled soxT, soxYZ or soxBC gene fragments, which were amplified by PCR from the thiosulfate- and tetrathionate-utilizing chemolithotrophic alphaproteobacterium Pseudaminobacter salicylatoxidans KCT001 (Mukhopadhyaya et al., 2000; Deb et al., 2004) using primers designed from the sox sequence of the bacterium (EMBL accession number AJ404005). This indicates the existence of a distinct sox genetic system in the new isolates that is unlikely to have any significant sequence similarity with the conserved sox gene cluster of alphaproteobacteria.

The new isolates were poorly distinguishable in terms of physiological and biochemical characteristics. Hence, comparison of AFLP patterns generated from sox PCR analysis was carried out, which also indicated that the isolates had a high degree of mutual genomic relatedness. Reproducible profiles were obtained for all isolates after gelelectrophoretic separation of the amplicons generated by PCR using different oligonucleotides bearing KCT001specific sequences from discrete regions of its sox gene cluster as arbitrary primer pairs. The profile generated from a PCR with one such primer pair, $\operatorname{sox} Y_{\text {Forward }}$ and sox $A_{\text {Reverse }}$, is shown as Supplementary Fig. S1 in IJSEM Online. Though the pairwise similarity coefficients $\left(S_{\mathrm{SM}}\right)$ determined from the AFLP patterns for all 12 strains by manual as well as computer-aided qualitative and quantitative comparison were above $80 \%$ (data not shown), the 12 strains could nonetheless be clustered into five genotypically related groups as follows: WT002 and WGT (represented by WGT); WPT, GT001, GT002, GT003 and GT004 (represented by WPT); 445b, 445c and 445d (represented by $445 \mathrm{c}$ ); and $\mathrm{WT} 001^{\mathrm{T}}$ and $445 \mathrm{a}$ in single-strain groups. These five representative strains (Table 1) were selected for detailed polyphasic investigation.

$16 \mathrm{~S}$ rRNA genes were amplified by PCR with bacteriaspecific primers f27 and r1492 (Gerhardt et al., 1994) from DNA samples or boiled cell extracts of the isolates using a High fidelity PCR master kit (Roche Applied Science) according to the manufacturer's instructions. 16S rRNA gene sequences from PCR products were determined using universal primers (Gerhardt et al., 1994), according to the manufacturer's specifications for Taq DNA polymeraseinitiated cycle sequencing reactions using fluorescently labelled dideoxynucleotide terminators with an ABI PRISM 377 automated DNA sequencer. 16S rRNA gene sequences of the new isolates were compared against those in the EMBL, GenBank and DDBJ databases using FASTA (version 3.4t23, 18 March 2004; Pearson \& Lipman, 1988). The $16 \mathrm{~S}$ rRNA gene sequences of the five strains were very similar to each other, showing $\geqslant 99 \%$ identity (Fig. 3 ). In contrast, the five strains had low levels (93-95\%) of 16S rRNA gene sequence similarity to species of the closest related genera, such as Alcaligenes, Pigmentiphaga, Pelistega, Taylorella, Bordetella and Achromobacter. Although the cluster of new sulfur-lithotrophic strains was phylogenetically closest to species of Alcaligenes, Pigmentiphaga, Pelistega, Taylorella, Bordetella and Achromobacter, the highest 16S rRNA gene sequence similarities found between the new isolates and any species of these genera were $95 \cdot 3,94 \cdot 9,94 \cdot 9$, $94 \cdot 6,94 \cdot 6$ and $94 \cdot 3 \%$, respectively. Multiple alignment of sequences was executed using CLUSTAL W (Thompson et al., 1994). Evolutionary distances (expressed in estimated numbers of changes per 100 nucleotides) were calculated by pairwise comparison of the aligned sequences (Jukes \& Cantor, 1969) by the DNADIST program. A consensus neighbour-joining tree (Saitou \& Nei, 1987) was

Table 1. Strains included in this study

LMG, Laboratorium voor Microbiologie, Universiteit Gent, Gent, Belgium; MTCC, Microbial Type Culture Collection, IMTECH, Chandigarh, India.

\begin{tabular}{|c|c|}
\hline Strain & Reference/source \\
\hline \multicolumn{2}{|l|}{ Tetrathiobacter kashmirensis } \\
\hline WT001 ${ }^{\mathrm{T}}\left(=\right.$ LMG $22695^{\mathrm{T}}=$ MTCC $\left.7002^{\mathrm{T}}\right)$ & Novel soil isolate from Jammu and Kashmir, India \\
\hline WGT ( = LMG 22696) & As above \\
\hline $445 \mathrm{a}$ & As above \\
\hline $445 c$ & As above \\
\hline WPT & As above \\
\hline Alcaligenes defragrans LMG $18538^{\mathrm{T}}$ & Foss et al. (1998) \\
\hline Pigmentiphaga kullae LMG $21665^{\mathrm{T}}$ & Blümel et al. (2001) \\
\hline Pelistega europaea LMG $10982^{\mathrm{T}}$ & Vandamme et al. (1998) \\
\hline Taylorella equigenitalis LMG $6222^{\mathrm{T}}$ & Sugimoto et al. (1983) \\
\hline Achromobacter xylosoxidans MTCC $491^{\mathrm{T}}$ & Yabuuchi et al. (1998) \\
\hline Alcaligenes faecalis MTCC $126^{\mathrm{T}}$ & Kersters \& De Ley (1984) \\
\hline Pseudaminobacter salicylatoxidans КСТ001 & Deb et al. (2004) \\
\hline
\end{tabular}




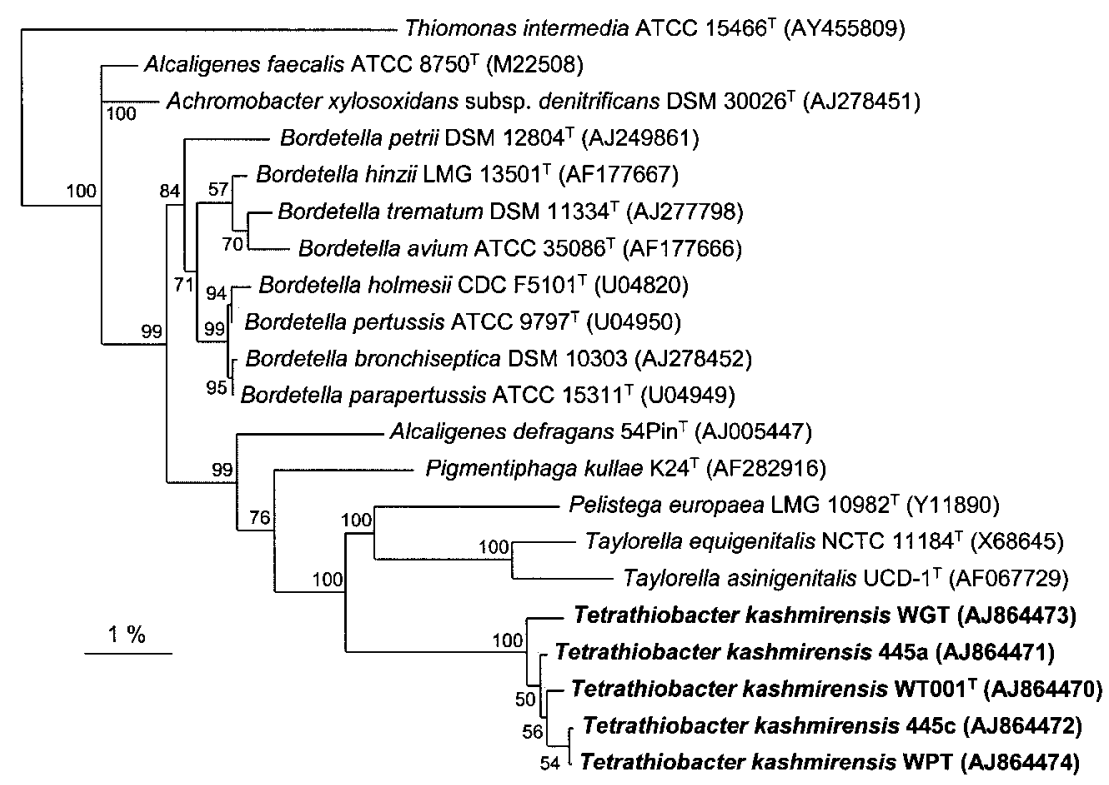

Fig. 3. Neighbour-joining tree showing the phylogenetic relationships between strains of Tetrathiobacter kashmirensis and selected strains from closely related taxa based on 16S rRNA gene sequences. The outgroup species Thiomonas intermedia belongs to another related betaproteobacterial cluster. Bar, $1 \%$ nucleotide difference. constructed following the majority rule and strict consensus out of 100 phylogenetic trees produced using the program NEIGHBOR in PHYLIP version 3.572c (Felsenstein, 1993). Bootstrap values (100 replicates) were calculated by the method of Felsenstein (1985) to validate the reproducibility of the branching pattern.

Phylogenetic analysis on the basis of 16S rRNA gene sequences (Fig. 3) clearly suggested that the five strains did not belong to and diverged from the classical branch of the family Alcaligenaceae (Yabuuchi et al., 1998), comprising Alcaligenes, Achromobacter and Bordetella species. Instead, the new strains were phylogenetically closest to Alcaligenes defragrans (95.3\%), Taylorella equigenitalis (95.2\%), Pelistega europaea (94.9\%) and Pigmentiphaga kullae $(94 \cdot 8 \%$ ) (in each case, strain 445 a had the highest similarity). In all the neighbour-joining trees constructed, the novel isolates formed a subtree with the two species of Taylorella and its closest relative, Pelistega europaea. Alcaligenes defragrans also clustered with the new strains, along with Pigmentiphaga kullae, and was found to be relatively distant from Alcaligenes faecalis ATCC $8750^{\mathrm{T}}$. From the high values of $16 \mathrm{~S}$ rRNA gene sequence similarity $(\geqslant 99 \%)$ observed between the new chemolithotrophic strains, together with their unequivocally low similarity to species of all the closest genera, it can be concluded that WT001 ${ }^{\mathrm{T}}$, WGT, WPT, 445a and $445 \mathrm{c}$ form a taxonomically coherent assemblage and represent a unique phylogenetic lineage. The stability of the cluster is also reflected in its bootstrap value of $100 \%$, which signifies that the five isolates form a consolidated and homogeneous phylogenetic group.

$5 S$ rRNA gene sequence analysis has previously demonstrated that the root of the 'Betaproteobacteria' is apparently located near the phylogenetic branch consisting of the strictly chemolithoautotrophic species now classified under the 'Gammaproteobacteria' (Lane et al., 1985). In our present study, however, the type strains of Alcaligenes defragrans, Alcaligenes faecalis, Achromobacter xylosoxidans, Pelistega europaea, Taylorella equigenitalis and Pigmentiphaga kullae tested negative for both oxidation and utilization of thiosulfate and tetrathionate, while 16S rRNA gene sequencebased phylogenetic analysis indicated that the cluster formed by the new chemolithotrophic isolates is distantly related to the sulfur lithotrophs of both the $\beta 1 \quad(<90 \%$ similarity) and $\gamma(<86 \%$ similarity) groups of the Proteobacteria. Preliminary studies showed that thiosulfate oxidation in the new isolates involved conversion of thiosulfate to tetrathionate, followed by accumulation and eventual oxidation of the latter to sulfate (Fig. 2b). The biochemical mechanism of thiosulfate as well as tetrathionate oxidation in the new isolates is likely to be similar to that employed by the beta- and gammaproteobacteria, following the tetrathionate intermediate $\left(\mathrm{S}_{4} \mathrm{I}\right)$ pathway (Kelly, 1989; Kelly et al., 1997). Most sulfur-oxidizing beta- and gammaproteobacterial species are obligately chemolithoautotrophic and/or extremophilic and hence are not amenable to genetic studies. The novel soil isolates reported here, being fastgrowing, nutritionally versatile, mesophilic, neutrophilic, tetrathionate-oxidizing facultatively chemolithotrophic betaproteobacteria, may well fit the bill and provide a system of choice for the investigation of the $\mathrm{S}_{4} \mathrm{I}$ pathway of thiosulfate oxidation as well as dissimilatory tetrathionate oxidation at the molecular level.

To determine the genomic relatedness of the new isolates, dot-blot hybridization experiments were carried out with DIG-labelled DNA as described previously (Labrenz et al., 2000) using the detection kit from Roche Applied Sciences following the manufacturer's instructions. Colorimetric quantification of dot intensities was done using the Molecular Analyst software (Bio-Rad) by determining mean pixel densities in equal-sized circles. Genomic DNA probes were 
prepared from the new isolates and a 100- to 1000-fold excess of the probe was used in hybridizing against frames of three to five target DNAs taken in quantitative triplicates of 25, 50 and $100 \mathrm{ng}$ at a time. The hybridization temperature was $60^{\circ} \mathrm{C}$ and the membranes were washed under highly stringent conditions (twice with $2 \times \mathrm{SSC} / 0 \cdot 1 \%$ SDS at room temperature for $10 \mathrm{~min}$; once with $0 \cdot 1 \times \mathrm{SSC} /$ $0 \cdot 1 \%$ SDS at $68^{\circ} \mathrm{C}$ for $\left.15 \mathrm{~min}\right)$. A high level of genomic relatedness (DNA-DNA hybridization values greater than or equal to $85 \%$ ) was observed between the new isolates, while the representative strain $\mathrm{WT} 001^{\mathrm{T}}$ exhibited uniformly low levels of DNA-DNA binding (between 10 and 15\%) with all the phylogenetically closest species.
In view of the high physiological, biochemical, phylogenetic and genetic similarities among the new isolates, fatty acid compositions were determined for $\mathrm{WT} 001^{\mathrm{T}}$ and WGT, which exhibited identical fatty acid profiles (no qualitative difference and $<0.5 \%$ quantitative variation). After an incubation period of $24 \mathrm{~h}$ at $30^{\circ} \mathrm{C}$ on LB agar, a loopful of well-grown cells was harvested and the preparation, separation and identification of fatty acids were performed using the Sherlock Microbial Identification System (Microbial ID, Inc.) at the DSMZ (Braunschweig, Germany). The fatty acids detected in strain $\mathrm{WT} 001^{\mathrm{T}}$ are listed in Table 2. Members of the Alcaligenaceae characteristically have large amounts of 16:0 and 17:0 cyclo and 14:0 3-OH fatty

Table 2. Fatty acid profile of Tetrathiobacter kashmirensis gen. nov., sp. nov. in comparison with related taxa

Taxa: 1, Tetrathiobacter kashmirensis WT001 ${ }^{\mathrm{T}}$ (data from this study); 2, range of values for strains of Alcaligenes faecalis (data from Dees \& Moss, 1975) and Alcaligenes defragrans (Foss et al., 1998); 3, Achromobacter xylosoxidans [range adapted from Dees \& Moss (1978) and Holmes et al. (1993)]; 4, Taylorella equigenitalis (Vandamme et al., 1998); 5, Pelistega europaea (Vandamme et al., 1998); 6, Pigmentiphaga kullae (Blümel et al., 2001). tr, Trace amount (<1\%) (for all species except Tetrathiobacter kashmirensis); -, not detected.

\begin{tabular}{|c|c|c|c|c|c|c|c|}
\hline \multirow[t]{2}{*}{ Fatty acid } & \multirow[t]{2}{*}{1} & \multirow[t]{2}{*}{2} & \multirow[t]{2}{*}{3} & \multirow[t]{2}{*}{4} & \multicolumn{2}{|c|}{5} & \multirow[t]{2}{*}{6} \\
\hline & & & & & Cluster I & Cluster II & \\
\hline Unknown (ECL 13·957) & $0 \cdot 24$ & - & - & - & - & - & - \\
\hline $14: 0$ & $0 \cdot 18$ & $4-8$ & $\leqslant 4$ & $\operatorname{tr}$ & $9 \cdot 7$ & $10 \cdot 8$ & 4 \\
\hline Summed feature $2^{*}$ & $10 \cdot 13$ & - & - & $10 \cdot 7 \dagger$ & $12 \cdot 7 \dagger$ & $12 \cdot 4 \dagger$ & $4 \cdot 6 \dagger$ \\
\hline Summed feature 3 & $28 \cdot 02$ & - & - & - & - & - & - \\
\hline $16: 1 \omega 7 c$ & - & - & - & $\operatorname{tr}$ & $21 \cdot 7$ & $41 \cdot 4$ & - \\
\hline $16: 0$ & $21 \cdot 69$ & $22-40$ & $21-35$ & $36 \cdot 8$ & $15 \cdot 7$ & $25 \cdot 2$ & $39 \cdot 9$ \\
\hline $17: 0$ cyclo & $3 \cdot 53$ & $4-28$ & $22-33$ & - & - & - & $21 \cdot 9$ \\
\hline $17: 0$ & $0 \cdot 27$ & $4-28$ & $\leqslant 6$ & - & - & - & - \\
\hline $16: 03-\mathrm{OH}$ & $0 \cdot 80$ & - & - & $\operatorname{tr}$ & $1 \cdot 2$ & $1 \cdot 2$ & - \\
\hline 19:0 cyclo $\omega 8 \mathrm{c}$ & $1 \cdot 32$ & - & - & - & - & - & $12 \cdot 2$ \\
\hline 19:0 10-methyl & $0 \cdot 18$ & - & - & $2 \cdot 2$ & $\operatorname{tr}$ & - & - \\
\hline $20: 1 \omega 7 c$ & $0 \cdot 34$ & - & - & - & - & - & - \\
\hline $10: 03-\mathrm{OH}$ & - & - & - & - & - & - & $2 \cdot 9$ \\
\hline $16: 02-\mathrm{OH}$ & - & - & $\leqslant 3$ & - & - & - & $4 \cdot 8$ \\
\hline Summed feature 1 & - & - & - & - & $\operatorname{tr}$ & $2 \cdot 7$ & - \\
\hline $15: 0$ & - & $<2$ & - & - & - & - & - \\
\hline $16: 1$ & - & $5-24$ & - & - & - & - & - \\
\hline $12: 02-\mathrm{OH}$ & - & $0-5$ & $<5$ & - & - & - & - \\
\hline $14: 02-\mathrm{OH}$ & - & $\leqslant 5$ & $\leqslant 7$ & - & - & - & - \\
\hline $18: 12-\mathrm{OH}$ & - & - & $2-12$ & - & - & - & - \\
\hline
\end{tabular}

${ }^{\star}$ Summed features consist of the following fatty acids, which could not be separated. Summed feature $1,14: 1 \omega 5 c$ and/or $\omega 5 t$; summed feature 2 ,

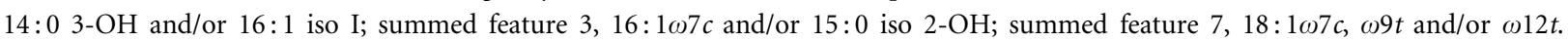

$\dagger$ Referred to as summed feature 3 in these studies.

$\ddagger$ See summed feature 7 . 
acids (Foss et al., 1998; Blümel et al., 2001), and the newly isolated strains synthesized significant amounts of these (Table 2). However, the new lithotrophs contained less than 4\% 17:0 cyclo, though 16:0 and 14:0 3-OH (as summed feature 2) were present in larger amounts (Table 2). The new strains are distinguished from their phylogenetic relatives by the presence of trace amounts of $20: 1 \omega 7 c$ and high concentrations of summed features 2 and 3 (Table 2).

Genomic DNA was hydrolysed with P1 nuclease and the nucleotides were dephosphorylated with bovine alkaline phosphatase. From the resulting deoxyribonucleosides, $\mathrm{G}+$ C contents (mol\%) were analysed using HPLC (Mesbah et al., 1989). The new isolates had $\mathrm{G}+\mathrm{C}$ contents ranging between 54.0 and $55 \cdot 2 \mathrm{~mol} \%$, which are distinct from all members of Alcaligenaceae except Alcaligenes faecalis, which has a G + C content of 56-59 mol\%. Phylogenetically, however, in a comparison with all other related genera, Alcaligenes faecalis was only distantly related to the new strains.

Comparison of all available phenotypic and chemotaxonomic characteristics of the five new isolates with their nearest phylogenetic relatives and numerical analysis of the data (UPGMA phenogram available as Supplementary Fig. S2 in IJSEM Online) corroborated the phylogenetic distinctiveness of the new cluster. Key physiological and biochemical characters that distinguish the new isolates from phylogenetically related species are shown in Table 3. It is evident from these findings that the new mesophilic and neutrophilic, facultatively chemolithotrophic, tetrathionateoxidizing isolates constitute a single phylogenetic and genomic group that merits generic treatment. They are hence classified in a new genus comprising a single species, for which we propose the name Tetrathiobacter kashmirensis gen. nov., sp. nov.

\section{Description of Tetrathiobacter gen. nov.}

Tetrathiobacter (Tet.ra.thi.o.bac'ter. Gr. adj. tetra four; Gr. n. thium sulfur; N.L. masc. n. bacter from Gr. neut. n. bakterion a rod; N.L. masc. n. Tetrathiobacter a tetrathionate-oxidizing bacterium).

Gram-negative, non-flagellated, oval to coccoid-shaped bacteria occurring singly or in pairs, chains, branched chains or clusters. Capsular coverings are present around cells of some strains. Cells are approximately $1 \cdot 0-1 \cdot 8 \mu \mathrm{m}$ long and $0 \cdot 6-1.5 \mu \mathrm{m}$ broad. Colonies are circular, entire, smooth, opaque and creamy white and develop central dark mounds that sometimes turn rusty red. Growth is observed between 10 and $42{ }^{\circ} \mathrm{C}$ and between $\mathrm{pH} 4 \cdot 5$ and $8 \cdot 5$. Oxidase, catalase and urease activities are observed, but not gelatinase activity. Facultatively chemolithoautotrophic organisms that use thiosulfate or tetrathionate as electron and energy source. Thiocyanate, soluble sulfides, elemental sulfur, sulfite and arsenite are not utilized as chemolithotrophic substrates. The DNA G + C content, as determined by HPLC, is $54-55 \cdot 2 \mathrm{~mol} \%$. The genus belongs to the 'Betaproteobacteria' and is phylogenetically closest to Alcaligenes defragrans, Taylorella equigenitalis, Pelistega europaea and Pigmentiphaga kullae. The type species is Tetrathiobacter kashmirensis. Until further taxa are identified, the genus comprises a single species.

Table 3. Phenotypic characteristics useful in differentiating Tetrathiobacter kashmirensis from related taxa

Species: 1, Tetrathiobacter kashmirensis; 2, Alcaligenes faecalis (data from Kersters \& De Ley, 1984); 3, Alcaligenes defragrans (Foss et al., 1998); 4, Achromobacter xylosoxidans (Yabuuchi et al., 1998); 5, Taylorella equigenitalis (Sugimoto et al., 1983); 6, Pelistega europaea (Vandamme et al., 1998); 7, Pigmentiphaga kullae (Blümel et al., 2001). +, Positive; -, negative; d, strain-dependent; NA, data not available.

\begin{tabular}{|c|c|c|c|c|c|c|c|}
\hline Characteristics & 1 & 2 & 3 & 4 & 5 & 6 & 7 \\
\hline \multicolumn{8}{|c|}{ Assimilation of single carbon compounds: } \\
\hline D-Glucose, D-xylose & + & - & - & + & - & - & - \\
\hline L-Arabinose, D-galactose, lactose & + & - & - & - & - & - & - \\
\hline Aesculin & - & - & NA & + & - & - & NA \\
\hline Urease activity & + & - & - & - & - & $\mathrm{d}$ & $\mathrm{NA}$ \\
\hline Growth at $42^{\circ} \mathrm{C}$ & + & + & - & + & - & + & + \\
\hline Chemolithotrophic growth on S & + & - & - & - & - & - & - \\
\hline Reduction of nitrate & + & - & + & + & - & - & $\mathrm{NA}$ \\
\hline $\mathrm{G}+\mathrm{C}$ content $(\mathrm{mol} \%)$ & $54-55 \cdot 2$ & $56-59$ & 67 & $66-69 \cdot 8$ & $36-37$ & $42-43$ & $68 \cdot 5$ \\
\hline
\end{tabular}

${ }^{\star}$ SF, Summed feature (for details see Table 2). 


\section{Description of Tetrathiobacter kashmirensis sp. nov.}

Tetrathiobacter kashmirensis (kash.mir.en'sis. N.L. masc. adj. kashmirensis of Kashmir, after the name of the province from where the original strains of the species were isolated.)

Can reduce nitrate to nitrite, utilize ammonium salts and urea but not glutamate, aspartate or nitrate as the nitrogen source and requires no yeast extract or vitamins for growth. Can grow in $1 \mathrm{M} \mathrm{NaCl}$. The following sole carbon compounds are assimilated chemo-organotrophically: succinate, citrate, malate, acetate, D-fructose, D-glucose, D-xylose, Dlactose, D-galactose, L-glutamate, L-lysine, L-arabinose and L-cysteine. None of following compounds are utilized: benzoate, sucrose, glycerol, L-histidine, L-leucine, Lisoleucine, myo-inositol, oxalate, mandelate, D-mannitol, D-raffinose, DL-lactate, L-tyrosine, L-threonine and Lserine. Utilization of D-mannose, D-maltose, L-arginine, Ltryptophan and L-aspartic acid as the sole carbon source is strain dependent. The following fatty acid components are present: $12: 0$, an unknown fatty acid having an equivalent chain-length of $13 \cdot 957,14: 0$, summed feature 2, summed feature $3,16: 0,17: 0$ cyclo, 17:0, 16:0 3-OH, $18: 1 \omega 7 c, 18: 0,19: 0$ cyclo $\omega 8 c, 19: 0$ 10-methyl and $20: 1 \omega 7 c$.

The type strain is WT001 ${ }^{\mathrm{T}}\left(=\mathrm{LMG} 22695^{\mathrm{T}}=\right.$ MTCC $7002^{\mathrm{T}}$ ) and its characteristics are as described above for the species. In addition, the type strain utilizes D-mannose, L-tryptophan and L-aspartic acid but not maltose or Larginine as single heterotrophic substrates. The $\mathrm{G}+\mathrm{C}$ content of the type strain is $55 \cdot 1 \mathrm{~mol} \%$ (by HPLC). All strains of the species identified to date have been isolated from bulk soils of a temperate orchard in Srinagar, Jammu and Kashmir, India.

\section{Acknowledgements}

This paper is only a small part of the wide perspectives and vision of the late Dr Pradosh Roy, whose untimely demise requires his unfortunate student W. G. to see the publication through on his behalf. We thank Mr Gourango Dey for his help in collecting the soil samples. We thank M/s Bangalore Genei for providing nucleotide sequencing services, the DSMZ for help in analysing fatty acid contents and the BCCM/LMG for determination of the $\mathrm{G}+\mathrm{C}$ contents of some of the strains. We acknowledge the experience shared by Mr Sanjib Gupta and Dr Jiaur Rehman Gayen and the assistance with electron microscopy provided by Mrs Tanima Modak, RSIC, Bose Institute. We thank Professor Timir Baran Samanta for his generous support during the final period of this work. W. G. was provided with a fellowship from a research project (number 37/1091/02-EMR-II) sponsored by the Council of Scientific and Industrial Research (CSIR), India. A. B. was supported by a fellowship of DBT, Govt of India, and S. M. and B. D. were supported by CSIR fellowships. Since its initiation, this work has been dedicated to Dr Chirajyoti Deb, whose exemplary spirit, sacrifice and relentless pursuit in the sphere of taxonomy of sulfur chemolithotrophs during the formative years of this laboratory serve as inspiration for the present generation of workers.

\section{References}

Appia-Ayme, C., Little, P. J., Matsumoto, Y., Leech, A. P. \& Berks, B. C. (2001). Cytochrome complex essential for photosynthetic oxidation of both thiosulfate and sulfide in Rhodovulum sulfidophilum. J Bacteriol 183, 6107-6118.

Blümel, S., Mark, B., Busse, H.-J., Kämpfer, P. \& Stolz, A. (2001). Pigmentiphaga kullae gen. nov., sp. nov., a novel member of the family Alcaligenaceae with the ability to decolorize azo dyes aerobically. Int J Syst Evol Microbiol 51, 1867-1871.

Das, S. K., Mishra, A. K., Tindall, B. J., Rainey, F. A. \& Stackebrandt, E. (1996). Oxidation of thiosulfate by a new bacterium, Bosea thiooxidans (strain BI-42) gen. nov., sp. nov.: analysis of phylogeny based on chemotaxonomy and $16 \mathrm{~S}$ ribosomal DNA sequencing. Int J Syst Bacteriol 46, 981-987.

Deb, C., Stackebrandt, E., Pradella, S., Saha, A. \& Roy, P. (2004). Phylogenetically diverse new sulfur chemolithotrophs of alpha-proteobacteria isolated from Indian soils. Curr Microbiol 48, 452-458.

Dees, S. B. \& Moss, C. W. (1975). Cellular fatty acids of Alcaligenes and Pseudomonas species isolated from clinical specimens. J Clin Microbiol 1, 414-419.

Dees, S. B. \& Moss, C. W. (1978). Identification of Achromobacter species by cellular fatty acids and by production of keto acids. J Clin Microbiol 8, 61-66.

Ezaki, T., Hashimoto, Y., Takeuchi, N., Yamamoto, H., Liu, S. L., Miura, H., Matsui, K. \& Yabuuchi, E. (1988). Simple genetic method to identify viridans group streptococci by colorimetric dot hybridization in microdilution wells. J Clin Microbiol 26, 1708-1713.

Felsenstein, J. (1985). Confidence limits on phylogenies: an approach using the bootstrap. Evolution 39, 783-791.

Felsenstein, J. (1993). PHYLIP - Phylogeny Inference Package, version 3.5c. Distributed by the author. Department of Genome Sciences, University of Washington, Seattle, USA.

Foss, S., Heyen, U. \& Harder, J. (1998). Alcaligenes defragrans sp. nov., description of four strains isolated on alkenoic monoterpenes $((+)$-menthene, alpha-pinene, 2-carene, and alphaphellandrene) and nitrate. Syst Appl Microbiol 21, 237-244.

Friedrich, C. G. (1998). Physiology and genetics of sulfur-oxidizing bacteria. Adv Microb Physiol 39, 235-289.

Friedrich, C. G. \& Mitrenga, G. (1981). Oxidation of thiosulfate by Paracoccus denitrificans and other hydrogen bacteria. FEMS Microbiol Lett 10, 209-212.

Friedrich, C. G., Rother, D., Bardischewsky, F., Quentmeier, A. \& Fischer, J. (2001). Oxidation of reduced inorganic sulfur compounds by bacteria: emergence of a common mechanism? Appl Environ Microbiol 67, 2873-2882.

Fuchs, T., Huber, H., Burggraf, S. \& Stetter, K. O. (1996). $16 \mathrm{~S}$ rDNA-based phylogeny of the archaeal order Sulfolobales and reclassification of Desulfurolobus ambivalens as Acidianus ambivalens comb. nov. Syst Appl Microbiol 19, 56-60.

Gerhardt, P., Murray, R. G. E., Wood, W. A. \& Krieg, N. R. (editors) (1994). Methods for General and Molecular Bacteriology. Washington, DC: American Society for Microbiology.

Holmes, B., Moss, C. W. \& Daneshvar, M. I. (1993). Cellular fatty acid compositions of "Achromobacter groups B and E". J Clin Microbiol 31, 1007-1008.

Jukes, T. H. \& Cantor, C. R. (1969). Evolution of protein molecules. In Mammalian Protein Metabolism, vol. 3, pp. 21-132. Edited by H. N. Munro. New York: Academic Press.

Katayama, Y., Hiraishi, A. \& Kuraishi, H. (1995). Paracoccus thiocyanatus sp. nov., a new species of thiocyanate-utilizing facultative 
chemolithotroph, and transfer of Thiobacillus versutus to the genus Paracoccus as Paracoccus versutus comb. nov. with emendation of the genus. Microbiology 141, 1469-1477.

Kelly, D. P. (1989). Physiology and biochemistry of unicellular sulfur bacteria. In Autotrophic Bacteria, pp. 193-217. Edited by H. G. Schlegel \& B. Bowien. Madison, WI: Science Tech Publishers. Berlin \& New York: Springer.

Kelly, D. P. \& Wood, A. P. (1994). Synthesis and determination of thiosulfate and polythionates. Methods Enzymol 243, 475-501.

Kelly, D. P. \& Wood, A. P. (2000). Reclassification of some species of Thiobacillus to the newly designated genera Acidithiobacillus gen. nov., Halothiobacillus gen. nov. and Thermithiobacillus gen. nov. Int J Syst Evol Microbiol 50, 511-516.

Kelly, D. P., Shergill, J. K., Lu, W.-P. \& Wood, A. P. (1997). Oxidative metabolism of inorganic sulfur compounds by bacteria. Antonie van Leeuwenhoek 71, 95-107.

Kelly, D. P., McDonald, I. R. \& Wood, A. P. (2000). Proposal for the reclassification of Thiobacillus novellus as Starkeya novella gen. nov., comb. nov., in the $\alpha$-subclass of the Proteobacteria. Int J Syst Evol Microbiol 50, 1797-1802.

Kersters, K. \& De Ley, J. (1984). Genus Alcaligenes Castellani and Chalmers 1919, 936 ${ }^{\mathrm{AL}}$. In Bergey's Manual of Systematic Bacteriology, vol. 1, pp. 361-373. Edited by N. R. Krieg \& J. G. Holt. Baltimore: Williams \& Wilkins.

Labrenz, M., Tindall, B. J., Lawson, P. A., Collins, M. D., Schumann, P. \& Hirsch, P. (2000). Staleya guttiformis gen. nov., sp. nov. and Sulfitobacter brevis sp. nov., $\alpha$-3-Proteobacteria from hypersaline, heliothermal and meromictic Antarctic Ekho Lake. Int J Syst Evol Microbiol 50, 303-313.

Lane, D. J., Stahl, D. A., Olsen, G. J., Heller, D. J. \& Pace, N. R. (1985). Phylogenetic analysis of the genera Thiobacillus and Thiomicrospira by 5 S rRNA sequences. J Bacteriol 163, 75-81.

McDonald, I. R., Kelly, D. P., Murrell, J. C. \& Wood, A. P. (1997). Taxonomic relationships of Thiobacillus halophilus, T. aquaesulis, and other species of Thiobacillus, as determined using 16S rDNA sequencing. Arch Microbiol 166, 394-398.

Mesbah, M., Premachandran, U. \& Whitman, W. B. (1989). Precise measurement of the $\mathrm{G}+\mathrm{C}$ content of deoxyribonucleic acid by high-performance liquid chromatography. Int J Syst Bacteriol 39, 159-167.
Moreira, D. \& Amils, R. (1997). Phylogeny of Thiobacillus cuprinus and other mixotrophic thiobacilli: proposal for Thiomonas gen. nov. Int J Syst Bacteriol 47, 522-528.

Mukhopadhyaya, P. N., Deb, C., Lahiri, C. \& Roy, P. (2000). A soxA gene, encoding a diheme cytochrome $\mathrm{c}$, and a sox locus, essential for sulfur oxidation in a new sulfur lithotrophic bacterium. J Bacteriol 182, 4278-4287.

Nathansohn, A. (1902). Über eine neue Gruppe von Schwefelbakterien und ihren Stoffwechsel. Mitt Zool Stn Neapel 15, 655-680 (in German).

Odintsova, E. V., Jannasch, H. W., Mamone, J. A. \& Langworthy, T. A. (1996). Thermothrix azorensis sp. nov., an obligately chemolithoautotrophic, sulfur-oxidizing, thermophilic bacterium. Int J Syst Bacteriol 46, 422-428.

Pearson, W. R. \& Lipman, D. J. (1988). Improved tools for biological sequence comparison. Proc Natl Acad Sci U S A 85, 2444-2448.

Saitou, N. \& Nei, M. (1987). The neighbor-joining method: a new method for reconstructing phylogenetic trees. Mol Biol Evol 4, 406-425.

Sneath, P. H. A. \& Sokal, R. R. (1973). Numerical Taxonomy. San Francisco: W. H. Freeman.

Sugimoto, C., Isayama, Y., Sakazaki, R. \& Kuramochi, S. (1983). Transfer of Haemophilus equigenitalis Taylor et al. 1978 to the genus Taylorella gen. nov. as Taylorella equigenitalis comb. nov. Curr Microbiol 9, 155-162.

Thompson, J. D., Higgins, D. G. \& Gibson, T. J. (1994). CLUSTAL W: improving the sensitivity of progressive multiple sequence alignment through sequence weighting, position-specific gap penalties and weight matrix choice. Nucleic Acids Res 22, 4673-4680.

Vandamme, P., Segers, P., Ryll, M. \& 8 other authors (1998). Pelistega europaea gen. nov., sp. nov., a bacterium associated with respiratory disease in pigeons: taxonomic structure and phylogenetic allocation. Int J Syst Bacteriol 48, 431-440.

Yabuuchi, E., Kawamura, Y., Kosako, Y. \& Ezaki, T. (1998). Emendation of the genus Achromobacter and Achromobacter xylosoxidans (Yabuuchi and Yano) and proposal of Achromobacter ruhlandii (Packer and Vishniac) comb. nov., Achromobacter piechaudii (Kiredjian et al.) comb. nov., and Achromobacter xylosoxidans subsp. denitrificans (Rüger and Tan) comb. nov. Microbiol Immunol 42, 429-438. 